\title{
Design of Polyhydroxyalkanoate (PHA) Microbeads with Tunable Functional Properties and High Biodegradability in Seawater
}

\section{Chloé Volant}

University of South Brittany: Universite de Bretagne-Sud

\section{Eric Balnois}

University of Western Brittany: Universite de Bretagne Occidentale

\section{Guillaume Vignaud}

University of South Brittany: Universite de Bretagne-Sud

\section{Anthony Magueresse}

University of South Brittany: Universite de Bretagne-Sud

\section{Stephane Bruzaud ( $\nabla$ stephane.bruzaud@univ-ubs.fr)}

University of South Brittany: Universite de Bretagne-Sud https://orcid.org/0000-0002-4576-7681

\section{Research Article}

Keywords: Polyhydroxyalkanoates, microbeads, surface properties, biodegradability, seawater

Posted Date: July 1st, 2021

DOl: https://doi.org/10.21203/rs.3.rs-627889/v1

License: (c) (i) This work is licensed under a Creative Commons Attribution 4.0 International License. Read Full License

Version of Record: A version of this preprint was published at Journal of Polymers and the Environment on November 25th, 2021. See the published version at https://doi.org/10.1007/s10924-021-02345-6. 


\section{Design of polyhydroxyalkanoate (PHA)}

\section{2 microbeads with tunable functional properties and}

\section{3 high biodegradability in seawater}

4 Chloé Volant $^{\mathrm{a}}$, Eric Balnois ${ }^{\mathrm{b}}$, Guillaume Vignaud ${ }^{\mathrm{a}}$, Anthony Magueresse ${ }^{\mathrm{a}}$, Stéphane Bruzaud ${ }^{\mathrm{a}}$

5 a Institut de Recherche Dupuy de Lôme (IRDL), UMR CNRS 6027, Université Bretagne Sud, Rue St

6 Maudé, 56100 Lorient, France

7

8

9

${ }^{\mathrm{b}}$ Laboratoire de Biotechnologie et Chimie Marines (LBCM), EA 3884, Université de Brest, Université de Bretagne Sud, Quimper, France

* E-mail address: stephane.bruzaud@univ-ubs.fr

\section{Abstract}

Commercial poly(3-hydroxybutyrate-co-3-hydroxyvalerate) (PHBHV) and poly(3hydroxybutyrate-co-3-hydroxyhexanoate) (PHBHHx) were used to prepare microbeads, with diameter ranging from 50 to $100 \mu \mathrm{m}$, by an emulsion-evaporation process. The properties of the beads reveal that the elaboration process enables the formation of spherical particles, that the crystallinity of the former polymer is not altered during the process and that the surface roughness of the particles can be tuned by changing the nature of the lateral chain in the PHA structure, in good correlation with its crystalline behavior. The mechanical properties of the different PHA beads are also found to be intimely linked with the crystalline content of the beads, with modulus varying between 1 to $7 \mathrm{GPa}$. All these properties are also governing the degradation behavior of these materials, as tested under marine environment. With a rapid degradation, similar to cellulose, and a degradation rate correlated with the crystalline content, 
these results emphasize the interest in developing PHA materials with tunable functions and degradation properties.

Keywords: Polyhydroxyalkanoates, microbeads, surface properties, biodegradability, seawater

\section{Introduction}

Microplastics are defined as solid plastic objects smaller than $5 \mathrm{~mm}$ in size, insoluble in water and not biodegradable [1]. Personal care products (PCPs) have been identified as a potential source of environmental pollution due to their high content in primary microplastics, with typical number and mass content about 2162 particles/g or $0.04 \mathrm{~g} / \mathrm{g}$ [2-4]. According to the PCPs' consumption, approximatively 1500 ton/year of micro plastics leach into the global aquatic environments, which account for $0.1 \%$ to $0.8 \%$ of the annual global release of primary microplastics in the world oceans [2]. Until recently, PCPs products are mainly formulated with conventional microplastics such as polyethylene, polypropylene, poly(ethylene terephthalate) or poly(methylmethacrylate) [5-9]. In order to limit their impact on the marine environment, many countries have attempt to ban the presence of these microplastics in rinse-off cosmetic products (United States in 2015, France and South Korea in 2016, Canada and New Zealand in 2017) [10-12]. These laws and decrees have led manufacturers to develop sustainable solutions with the use of particles or beads, for example in exfoliation products, such as natural organic ingredients including plant or fruits hulls, kernels seeds, microcrystalline cellulose or the use of mineral particles such as silica or pumice stone [13, 14]. If these additives have the benefit to being natural and biodegradable materials compared to conventional polymers $[15,16]$, they nonetheless also present drawbacks because of their irregular shapes and size; they are generally colored, not or poorly stable in aqueous medium, with an inadequate hardness and their commercial quantity and availability are rather limited [17]. The cosmetic industry is thus interested in developing biodegradable particles in the micrometer size range for applications such as facial cleaning or scrub [5$8,13,42,43]$ having a smoother action than natural crushed ingredients $[18,19]$.

Polyhydroxyalkanoates (PHA) which are bacterial polyesters produced by bacterial fermentation in particular in marine environment [20] are natural candidates for applications in cosmetic meeting 
environmental constraints. In addition depending on the bacteria, stress conditions and substrates, a broad variety of PHA can be produced with different monomer units and thus leading to a variety of chemical and physical properties [18]. These properties can be modulated as a function of the chemical composition or length of the lateral chain, of the proportion of the monomer units and their distribution all along the polymer chain [19]. For example, Lemechko et al. [20] obtained poly(3-hydroxybutyrateco-3-hydroxyvalerate) (PHBHV) macromolecules by optimizing the choice of carbon source (agroressources effluents) and the amount of valeric acid to produce a range of polymers with a controlled proportion of each monomer. The thermal properties showed a decrease of enthalpy of fusion as the hydroxyvalerate unit (HV) content increases. By increasing the proportion of $\mathrm{HV}$ monomer (from 5\% up to $20 \%$ ), the PHBHV polymer becomes more ductile with a decreasing of the glass transition temperature $\left(\mathrm{T}_{\mathrm{g}}\right)$ and crystalline rate [21]. Poly(3-hydroxybutyrate-co-3-hydroxyhexanoate) (PHBHHx) is another kind of commercially available PHA. The substitution of the hydroxyvalerate unit by an hexanoate unit $(\mathrm{HHx})$ induces changes in the polymer properties, the polymeric material becomes more ductile and stiffer $[22,23]$. The $T_{\mathrm{g}}$ parameter is also affected by varying the rate and chemical structure of the unit of the copolymer [23]. For example, increasing the proportion of HHx from 7 to $18 \%$ decreases the glass transition temperature [24-26]. As a consequence of both phenomena, it has been reported that the degree of crystallinity, in the presence of HHx unit, becomes lower due to a disruption in the PHB crystal arrangement. The HHx unit generates a greater steric hindrance than HV units, the degree of crystallinity varies from $54 \%$ (with $5 \% \mathrm{HV}$ ) to $27 \%$ (with $7 \% \mathrm{HHx}$ ) [27]. Furthermore the crystalline rate of PHBHHx also decreases as the percentage of HHx unit increases from 4 to $20 \%$, some authors have noted a decrease of 41 to $25 \%$ [26], while others have measured a decrease of 64 to $3 \%$ [28].

Several methods have been described for the production of biopolymers microparticles $[29,30]$ such as emulsification, gelation, drying, coacervation or precipitation. The choice of the method and then of the proceeding and formulation parameters influence the physico-chemical characteristics of the particles such as the porosity, sphericity, size, dispersity, surface appearance or shape of the particles [31-36]. The type of polymer, in particular its botanical origin, affects the size of the so-formed microparticles. 
This has been demonstrated for starch-based particles obtained by nanoprecipitation [31]. The process of elaboration of the micro and nanoparticle is also a fundamental parameter that govern the final properties of the beads. For example, it has been shown that ultrasound process allows to obtain small PHB microbeads in comparison with a stirring process, with diameter of $0.14 \mu \mathrm{m}$ and $32 \mu \mathrm{m}$ respectively [32]. The size and sphericity are also influenced by the choice of solvent. For example, dichloromethane allows to obtain more homogeneous PHBHV microbeads than chloroform $(0.8-7 \mu \mathrm{m}$ and $0.1-0.4 \mu \mathrm{m})$ [33]. Other authors have shown that the size of PHBHV microbeads can be tuned by adjusting the surfactant concentration, obtaining a range of microbeads from $389 \mu \mathrm{m}$ to $39 \mu \mathrm{m}$ for 0.5 to $4 \%$ PVA [35]. The porosity of PHB-based microbeads is also found to be dependent on the amount of aqueous phase, used in an emulsification process [32]. The final process of the bead fabrication, the solvent evaporation process including the time and temperature, is also an important step in determining the final properties of the particles [32]. The biomedical domain is certainly the one that has contributed to the most significant results in the elaboration of PHA microparticles [37]. In a majority of studies on PHA particles, the emulsification process was developed to elaborate micrometer size particles made from PHBHV or PHBHHx polymer. Table 1 sums up some of the main parameters used in these processes.

Table 1: List of the different parameters used to elaborate PHBHV or PHBHHx microparticles using the emulsification process and their applications. NS means not specified.

\begin{tabular}{|c|c|c|c|c|c|c|c|}
\hline $\begin{array}{l}\text { Type of } \\
\text { polymer }\end{array}$ & $\begin{array}{l}\text { Polymer } \\
\text { solution }\end{array}$ & $\begin{array}{c}\text { Surfactant } \\
\text { solution }\end{array}$ & Stirring & $\begin{array}{c}\text { Evaporation } \\
\text { of the organic } \\
\text { solvent }\end{array}$ & $\begin{array}{c}\text { Microbeads } \\
\text { size } \\
\text { distribution, } \\
\mu \mathrm{m}\end{array}$ & Applications & References \\
\hline PHBHV & $\begin{array}{l}5 \% \mathrm{w} / \mathrm{v} \text { in } \\
\text { chloroform }\end{array}$ & $\begin{array}{c}2 \% \mathrm{w} / \mathrm{v} \text { aqueous } \\
\text { PVA }\end{array}$ & $\begin{array}{c}\text { Mechanical stirring } \\
\text { (3000 rpm) }\end{array}$ & $\begin{array}{c}\text { Mechanical } \\
\text { stirring (800 } \\
\text { rpm) for } 4 \text { to } 7 \\
\text { h }\end{array}$ & $21 \mu \mathrm{m}$ & $\begin{array}{c}\text { Encapsulation of } \\
\text { andiroba oil }\end{array}$ & [38] \\
\hline PHBHV & $\begin{array}{c}1.0 \% \mathrm{w} / \mathrm{v} \text { in } \\
\text { chloroform } \\
\text { solution }\end{array}$ & $\begin{array}{l}1.0-3.0 \% \mathrm{w} / \mathrm{v} \\
\text { aqueous PVA }\end{array}$ & Mechanical stirring & $\begin{array}{c}\text { Mechanical } \\
\text { stirring at } 300 \\
\text { rpm or } 900 \\
\text { rpm, }\end{array}$ & $3-30 \mu \mathrm{m}$ & $\begin{array}{l}\text { Encapsulation of } \\
\text { coumarin-6 (C6) } \\
\text { or pyrene (Py) }\end{array}$ & [36] \\
\hline
\end{tabular}




\begin{tabular}{|c|c|c|c|c|c|c|c|}
\hline & & & & $\begin{array}{l}\text { continuously, } \\
\text { for } 24 \mathrm{~h}\end{array}$ & & & \\
\hline PHBHV & $\begin{array}{c}0.88-5.12 \mathrm{~g} \mathrm{~mL}^{-1} \\
\text { in chloroform }\end{array}$ & $\begin{array}{c}0.38-4.60 \% \\
\text { g.mL-1 aqueous } \\
\text { PVA }\end{array}$ & Mechanical stirring & $\begin{array}{c}\text { Mechanical } \\
\text { stirring at } 1400 \\
\text { rpm and for } 4 \mathrm{~h}\end{array}$ & 4-19 $\mu \mathrm{m}$ & $\begin{array}{c}\text { Encapsulation of } \\
\text { flurbiprofen }\end{array}$ & [39] \\
\hline PHBHV & $\begin{array}{l}2,5 \% \mathrm{w} / \mathrm{v} \text { in } \\
\text { chloroform }\end{array}$ & $\begin{array}{c}1 \% \text { aqueous } \\
\text { PVA }\end{array}$ & $\begin{array}{c}\text { Mechanical stirring } \\
\text { (1000 rpm) }\end{array}$ & $\begin{array}{c}\text { Rotary } \\
\text { evaporator }\end{array}$ & $9 \mu \mathrm{m}$ & $\begin{array}{l}\text { Encapsulation of } \\
\text { annatto extract }\end{array}$ & {$[40]$} \\
\hline PHBHV & $\begin{array}{l}1 \% \mathrm{w} / \mathrm{v} \text { in } \\
\text { chloroform }\end{array}$ & $\begin{array}{c}2 \%(\mathrm{w} / \mathrm{v}) \\
\text { aqueous PVA }\end{array}$ & $\begin{array}{c}\text { Mechanical stirring } \\
(1000-4000 \mathrm{rpm})\end{array}$ & $\begin{array}{c}\text { Vacuum } \\
\text { distillation } \\
\text { unit, and } \\
\text { heated to } 45^{\circ} \mathrm{C}\end{array}$ & $10-300 \mu \mathrm{m}$ & $\begin{array}{l}\text { Encapsulation of } \\
\text { trypan blue dye }\end{array}$ & {$[41]$} \\
\hline PHBHV & $\begin{array}{c}2 \% \mathrm{w} / \mathrm{v} \text { in } \\
\text { dichloromethane }\end{array}$ & $\begin{array}{l}1 \% \text { aqueous } \\
\text { PVA (w/v) }\end{array}$ & Dropwise fashion & $\begin{array}{c}900 \text { rpm for } 8 \mathrm{~h} \\
\text { at room } \\
\text { temperature } \\
\text { with a 3-bladed } \\
\text { propeller in an } \\
\text { off-centre } \\
\text { position }\end{array}$ & $20-40 \mu \mathrm{m}$ & $\begin{array}{c}\text { Encapsulation of } \\
\text { diazepam }\end{array}$ & {$[42]$} \\
\hline PHBHV & $\begin{array}{l}0.05-0.20 \mathrm{~g} \text { in } 5 \\
\mathrm{~mL} \text { chloroform }\end{array}$ & $\begin{array}{c}1.0-1.2 \% \\
\text { aqueous PVA }\end{array}$ & $\begin{array}{c}\text { Mechanical stirring } \\
\text { (1000 rpm) }\end{array}$ & $12 \mathrm{~h}$ at $25^{\circ} \mathrm{C}$ & $20-60 \mu \mathrm{m}$ & $\begin{array}{c}\text { Encapsulation of } \\
\text { rifampicin }\end{array}$ & [43] \\
\hline PHBHV & $\begin{array}{l}0.5 \% \text { in } \\
\text { chloroform }\end{array}$ & $\begin{array}{c}0-4 \% \mathrm{w} / \mathrm{v} \\
\text { aqueous PVA }\end{array}$ & NS & $\begin{array}{l}700 \mathrm{rpm} \text { and } \\
50^{\circ} \mathrm{C} \text { for } 6 \\
\text { hours }\end{array}$ & $31-390 \mu \mathrm{m}$ & $\begin{array}{c}\text { Process effects on } \\
\text { degradation in } \\
\text { vitro }\end{array}$ & {$[35]$} \\
\hline PHBHV & $\begin{array}{l}100 \mathrm{mg} / \mathrm{mL} \\
\text { chloroform }\end{array}$ & $\begin{array}{c}1-4 \% \mathrm{w} / \mathrm{v} \\
\text { aqueous PVA }\end{array}$ & $\begin{array}{c}\text { Mechanical stirring } \\
\text { (500 rpm) }\end{array}$ & $\begin{array}{l}\text { Nitrogen } \\
\text { atmosphere } \\
\text { was created in } \\
\text { the flask and } \\
\text { the solution } \\
\text { was stirred } \\
\text { until all the } \\
\text { chloroform was } \\
\text { evaporated. }\end{array}$ & $322-538 \mu \mathrm{m}$ & $\begin{array}{c}\text { Encapsulation of } \\
\text { tetracycline }\end{array}$ & [44] \\
\hline PHBHHx & Dichloromethane & Aqueous SDS & NS & $\begin{array}{c}\text { Magnetic } \\
\text { stirring at room } \\
\text { temperature }\end{array}$ & $5-20 \mu \mathrm{m}$ & $\begin{array}{l}\text { Encapsulation of } \\
\text { 5-fluorouracil or } \\
\text { cyclosporin A }\end{array}$ & [45] \\
\hline
\end{tabular}




\begin{tabular}{|c|c|c|c|c|c|c|c|}
\hline PHBHHx & $\begin{array}{c}0.1 \% \mathrm{w} / \mathrm{v} \text { in } \\
\text { acetone }\end{array}$ & ND & Vigorous stirring & $\begin{array}{c}\text { Under vacuum } \\
\text { at } 35^{\circ} \mathrm{C} \\
\text { overnight }\end{array}$ & $75 \mu \mathrm{m}$ & $\begin{array}{c}\text { Effect of PHA } \\
\text { particles on cell } \\
\text { growth }\end{array}$ & [46] \\
\hline
\end{tabular}

93

The objective of this work is to synthetize PHA microparticles for cosmetic applications with the following goals: size of approximately $100 \mu \mathrm{m}$, spherical shape particle with tunable surface aspect and mechanical properties and presenting good biodegradation properties in the marine environment. Surprisingly, to the best of our knowledge, the development of PHA microparticles for such application is poorly described. Three commercial PHA, of different chemical structures, were used to prepare microbeads by emulsion-evaporation process. The physico-chemical properties of the different beads were then studied, in terms of shape, crystallinity, surface and mechanical properties as well as biodegradability and compared with PLA microparticles used as control.

Among these 3 selected PHA, one (PHBHV) is readily available commercially while the other 2 (the both PHBHHx) are not. In these conditions, this prospective study will make it possible to consider expanding the range of applications of these PHA, especially for the both PHBHHx which are a new PHA kind, and find new potential uses for these PHA.

\section{Materials and methods}

\subsection{Materials}

Poly(3-hydroxybutyrate-co-hydroxyvalerate) (PHBHV) with 3 mol\% in HV was supplied by Tianan Biological Materials Co. Ltd. (China), under the trade name ENMAT Y1000P. Poly(3-hydroxybutyrateco-hydroxyhexanoate) (PHBHHx) with 6 mol\% in HHx and PHBHHx with 11 mol \% in HHx were supplied by Kaneka Corporation (Japan), under the trade name Aonilex X131A and Aonilex X151A, respectively. Polylactic acid (PLA) was purchased from NatureWorks under the trade name Ingeo 7001D. The physico-chemical properties of the investigated commercial polymers are given in Table 2. For clarification in the following text, the notation PHBHV, PHBHHx (6\%) and PHBHHx (11\%) and PLA will be used. All chemicals products and reagents used in these experiments were analytical grade and were purchased from Sigma-Aldrich. 
Table 2: Physico-chemical characteristics of PHBHV, PHBHHx $(6 \%$ and $11 \% H H x)$ and PLA pellets

\begin{tabular}{|c|c|c|c|c|c|c|c|}
\hline Polymer & Chemical structure & $\begin{array}{c}\text { Average } \\
\text { molecular mass } \\
\left(\times 10^{3} \mathrm{~g} \mathrm{~mol}^{-1}\right)\end{array}$ & PDI & $\mathbf{X}_{\mathrm{c}}(\%)$ & $\begin{array}{l}\mathrm{Tm} \\
\left({ }^{\circ} \mathrm{C}\right)\end{array}$ & $\begin{array}{c}\mathrm{Tg} \\
\left({ }^{\circ} \mathrm{C}\right)\end{array}$ & References \\
\hline $\begin{array}{l}\text { PHBHV } \\
(3 \% \mathrm{HV})\end{array}$ & & $340-400$ & $2.5--2.7$ & $54-65$ & $165-175$ & $4-8$ & {$[27,47]$} \\
\hline $\begin{array}{l}\text { PHBHHx } \\
(6 \% \mathrm{HHx})\end{array}$ & & $345-452$ & $1.9-2.6$ & 27 & $142-145$ & 2 & $\begin{array}{c}\text { [27] } \\
\text { Technical sheet } \\
\text { from Kaneka }\end{array}$ \\
\hline $\begin{array}{l}\text { PHBHHx } \\
(11 \% \text { HHx) }\end{array}$ & & $550-614$ & $2.0-2.4$ & 34 & $126-136$ & $0-2$ & $\begin{array}{c}\text { [48-50] } \\
\text { Technical sheet } \\
\text { from Kaneka }\end{array}$ \\
\hline $\begin{array}{c}\text { PLA } \\
(4 \% \text { D- } \\
\text { lactide) }\end{array}$ & & $174-220$ & $1.6-1.8$ & 5 & $150-160$ & $55-60$ & $\begin{array}{c}\text { [51-54] } \\
\text { Technical sheet } \\
\text { from NatureWorks }\end{array}$ \\
\hline
\end{tabular}

Microparticules of PHBHV, PHBHHx (6\% and 11\%) and PLA were elaborated by emulsification process. PHBHV was dissolved at $50 \mathrm{~g} \mathrm{~L}^{-1}$ in chloroform under reflux conditions $\left(50{ }^{\circ} \mathrm{C}\right)$, PHBHHx and PLA were dissolved at the same concentration but in dichloromethane under reflux conditions $\left(40{ }^{\circ} \mathrm{C}\right)$ during 24 hours. These polymer solutions were then slowly added in an aqueous solution of polyvinyl alcohol (2\%) under mechanical stirring $(4000 \mathrm{rpm})$. The emulsion time was fixed at $15 \mathrm{~min}$. The particles were then dried by gently evaporating the solvent under continuous magnetic stirring during 24 hours. The dried particles were collected by sequential sieving (Inox sieve with $250 \mu \mathrm{m}$ and $50 \mu \mathrm{m}$ mesh, Granuloshop, Chatou, France), washed several times with deionized water and lyophilized.

\subsection{Characterization of the microparticles}

The morphology of the microbeads was analyzed by a scanning electron microscope (JSM-IT500HR from JEOL). SEM observations were carried out with secondary electron detector at an acceleration voltage of $3 \mathrm{kV}$. The particles were stuck on adhesive carbon tape, then gold-coated using a sputter coater (Scancoat6 from Edwards). The quantitative determination of the microbeads diameter and their 
shape was performed form image analysis following SEM observation. For each sample, a minimum of 500 microparticles were analyzed using ImageJ software (version 1.52, NIH) The circularity factor (CF) was determined using Equation (1):

$$
C F=\frac{4 \pi \times \text { area }}{(\text { perimeter })^{2}}
$$

The surface topographies of the microbeads were also evaluated by Atomic Force Microscopy (AFM). AFM measurements were obtained with a multimode 8 atomic force microscope (Bruker, Santa Barbara, CA) operated on the scanasyst@ mode (Bruker) under ambient conditions $\left(23{ }^{\circ} \mathrm{C}, \mathrm{RH}=50 \%\right)$. Standard scanasyst tips (Bruker), with a resonance frequency of $70 \mathrm{KHz}$ and a spring constant of $0.4 \mathrm{~N} / \mathrm{m}$ were used. Images were analyzed using the Nanoscope analysis software (V1.80). To ensure a good reproducibility in the measurements, for each sample, a minimum of three areas were investigated for each microbead, and for each sample a minimum of five different microbeads were observed.

\subsubsection{Thermal properties}

Thermal properties were analyzed by Differential Scanning Calorimetry (DSC). About 5-8 mg were introduced in standard aluminium pans, using Mettler-Toledo DSC882 equipment. Samples were heated from $25^{\circ} \mathrm{C}$ to $180^{\circ} \mathrm{C}$ at a scanning rate of $10^{\circ} \mathrm{C} \mathrm{min}^{-1}$ under nitrogen flow. Thermal characteristics were recorded such as transition temperatures (melting, crystallization and glass temperatures) and melting enthalpy $\left(\Delta \mathrm{H}_{\mathrm{m}}\right)$. Each sample was analyzed in triplicate.

\subsubsection{Infra-red spectroscopy}

Attenuated Total Reflection Fourier Transform Infrared (spectrophotometer ????) (ATR-FTIR Vertex70v, Bruker) was operated in the range from 4000 to $600 \mathrm{~cm}^{-1}$ with $4 \mathrm{~cm}^{-1}$ resolution. Dried microbeads were deposited directly on to the diamond crystal. For each sample, a minimum of 16 scans were performed to ensure a good reproducibility in the signals.

\subsubsection{Nanomechanical properties}

Nanoindentation experiments were obtained with a Nanoindenter XP from MTS Nano Instruments equipped with a three-side pyramid (Berkovich) indenter, as previously described [55]. All Experiments 
were conducted under ambient conditions $\left(23^{\circ} \mathrm{C}, \mathrm{RH} 50 \%\right)$ and using the continuous stiffness measurement (CSM) method with the following parameters: $3 \mathrm{~nm}$ amplitude and $45 \mathrm{~Hz}$ oscillations using a $0.05 \mathrm{~s}^{-1}$ loading rate. Measurements were taken at depths to $1500 \mathrm{~nm}$. A Poisson's ratio of 0 was used in all modulus calculations. For each sample, around 75 indents were performed with $5 \times 5$ matrix on different locations; average values of both elastic modulus and hardness were then calculated from curves according to the method of Oliver and Pharr [56]. Experiments were performed on polymer pellets included in an epoxy resin, polished prior experiments.

The AFM technique was also used to probe the nanomechanical properties of the polymer microbeads using the PeakForce Quantitative Nanomechanical Measurements (PFQNM). In PFQNM, the piezo of the AFM is vertically oscillating at a frequency of $2 \mathrm{kHz}$, with an amplitude of $150 \mathrm{~nm}$. While the piezo move the sample beneath the tip in the $\mathrm{X}$ and $\mathrm{Y}$ direction, a force curve is recorded in every coordinate, allowing to extract mechanical properties from the materials. The spring constant of RTESP-525 commercial tips were evaluated using the Sader method (https://sadermethod.org) and the tip radius was determined using the relative calibration method. A polystyrene film of $2.7 \mathrm{GPa}$ was used as a standard of calibration (PFQNM SPM kit-12M, Bruker). The peak force setpoint was typically set at $200 \mathrm{nN}$.

The indentation modulus was calculated using the Dejarguin-Muller-Toporov (DMT) model and extracted using the nanoscope image analysis software (V1.80). For each sample, a minimum of three areas were recorded and for each polymer, a minimum of three different bead were analyzed.

\subsubsection{Biodegradability}

Biodegradability of microbeads was determined with the NF EN ISO 19679 test that measures aerobic biodegradation of non-floating plastics at the seawater / sediment interface. The amount of total organic carbon contained in each sample $\left(m_{C_{2, \text { theorical }}}\right)$ was determined by elemental analysis. The mass percentage is $44.44 \pm 0.02$ for micronized cellulose, $55.18 \pm 0.02$ for PHBHV, $56.52 \pm 0.25$ for PHBHHx (6\%), $57.08 \pm 0.18$ for PHBHHx (11\%) and $49.59 \pm 0.17$ for the PLA.

Sample preparation was previously described for solid/liquid state, as an adaptation of the Strum test [57]. Under continuous oxygenation in a sealed closed system, a first compartment contains the 
microbeads in a mixture of seawater $(100 \mathrm{~mL})$ and sediment $(30 \mathrm{~g})$, and the second an absorbing solution with a $\mathrm{NaOH}$ solution $\left(20 \mathrm{~mL}, 0.2 \mathrm{~mol} \mathrm{~L}^{-1}\right)$ and distilled water $(20 \mathrm{~mL})$. A blank flask with no sample is included in each test set up to determine the blank respiration of the seawater, as well as a standard composed of micronized cellulose to validate the results of the test. The test was carried out for 250 days in a water bath at $25^{\circ} \mathrm{C}$.

Since the produced carbon only comes from the biodegraded sample, the trapped $\mathrm{CO}_{2}$ by the absorbing solution is proportional to the amount of carbon consumed. The product sodium carbonate by the reaction of $\mathrm{CO}_{2}$ and $\mathrm{NaOH}$ is precipitated by a $\mathrm{BaCl}_{2}$ solution. The remaining $\mathrm{NaOH}$ is titrating with hydrochloric acid $\left(0.1 \mathrm{~mol} \mathrm{~L}^{-1}\right)$ to determine the $\mathrm{CO}_{2}$ trapped by the absorbing solution. Rate of biodegradation $\left(\% \mathrm{CO}_{2}\right)$ was determined from the Equation (2):

$$
\% \mathrm{CO}_{2}=\frac{\left(m_{\mathrm{CO}_{2, \text { sample }}}-m_{\mathrm{CO}_{2, \text { control }}}\right) \times 100}{m_{\mathrm{CO}_{2, \text { theorical }}}}
$$

Where $m_{\mathrm{CO}_{2, \text { sample }}}$ is the amount of $\mathrm{CO}_{2}$ produced in the sample test, $m_{\mathrm{CO}_{2, \text { control }}}$ is the amount of $\mathrm{CO}_{2}$ produced in blank test.

\section{Results and discussion}

\subsection{Morphology of microbeads}

SEM images of the different microbeads are presented in Figure 1. All the beads are spherical, as revealed by a circularity factor close to 1 (Table 3). The diameter of the beads (Table 3 ) is found to be dependent on the polymer nature, thus indicating that, for a similar elaboration process, using identical parameters, the chemical nature of the polymer controls the final size of the bead. PHBHV and PLA microbeads are the largest particles, with diameter around $100 \mu \mathrm{m}$, whereas PHBHHx particles have smaller diameters, that also decrease with a lower content in HHx. The large standard deviation measured on our samples may be associated with the elaboration process but also to the limited the number of particles measured by image analysis. These diameters are nonetheless consistent with other types of microparticles obtained using a similar process and determined by SEM or optical microscopy [16]. 
Table 3: Mean diameter and circularity factor of the microparticles as determined from SEM image analysis. The average diameter and standard deviation were estimated on more than 500 particles.

\begin{tabular}{|c|c|c|}
\hline Microbeads & $\begin{array}{c}\text { Microbeads size distribution }(\boldsymbol{\mu m}) \\
\text { (mean diameter } \pm \text { SD) }\end{array}$ & Circularity factor \\
\hline PHBHV & $94 \pm 25$ & 0.91 \\
\hline PHBHHx (6\%) & $48 \pm 20$ & 0.93 \\
\hline PHBHHx (11\%) & $75 \pm 25$ & 0.92 \\
\hline PLA & $111 \pm 42$ & 0.93 \\
\hline
\end{tabular}

From the SEM images, the surface roughness can be qualitatively observed. The SEM images at different resolution (Figure 1) reveals that the PLA bead is rather smooth in comparison with the rough surfaces of PHBHHx or PHBHV. The roughness was quantitatively estimated by means of the AFM, on area of approximatively $25 \mu \mathrm{m}^{2}$. It should be noted here that stable AFM images were difficult to obtained on larger scale $\left(>25 \mu \mathrm{m}^{2}\right)$ due to instabilities generated by the topography on top of each bead and the variation in height imposed by the radius of curvature of the beads. Figure 2 presents AFM images obtained of the top of the different beads and their corresponding surface analysis, confirming the smooth topography of the PLA beads and the important roughness of the PHA beads. At such scan size, the roughness between $\sim 130-210 \mathrm{~nm}$ is obtained for the three PHA particles whereas a roughness of only $25 \mathrm{~nm}$ is obtained for the PLA. This observation is well correlated with the maximum height, Rmax, measured on these images, showing the large distribution in height for the PHA particles (up to $1 \mu \mathrm{m})$ and the relatively small height distribution for the PLA particle $(200 \mathrm{~nm})$. The roughness of the PHA particles can be associated with the semi-crystalline character of the polymer and fast precipitation induced by the rapid evaporation of the solvent. This trend was also reported in other studies but not quantified [58, 59]. Finally, it should also be mentioned, that considering scan area of $25 \mu \mathrm{m}^{2}$, no differences in RMS can be attributed to the different PHA beads indicating that the crystallites of PHBHV and PHBHHx are forming similar surface structures on the periphery of the bead, considering the RMS and topographic point of view. 
The thermal properties of the four microbeads are reported in Table 4. Characteristic values are determined from the first heating to observe the effect of the elaboration process on the final properties of the beads. No difference can be observed between the thermal properties of the beads and of the original polymer pellets. PHA microbeads have a glass transition temperature around $0{ }^{\circ} \mathrm{C}$. PHBHV exhibits one melting temperature at about $173{ }^{\circ} \mathrm{C}$. Two melting peaks were detected for the PHBHHx sample, at 125 and $144{ }^{\circ} \mathrm{C}$ for PHBHHx (6\%) and 109 and $137{ }^{\circ} \mathrm{C}$ for the PHBHHx (11\%), attributed to the PHB segment melting temperature and to the PHHx segment melting temperature, respectively. These values are similar to the literature data [23, 24, 27, 39]. In contrast, PLA microbeads exhibits glass transition temperature around $60-63^{\circ} \mathrm{C}$ ${ }^{\circ} \mathrm{C}$, and a melting temperature of $147^{\circ} \mathrm{C}$

${ }^{\circ} \mathrm{C}$. These results are also in good agreement with those described for amorphous PLA microbeads obtained by emulsionevaporation in the presence of dichloromethane [33].

Table 4: Thermal characteristics of the different microbeads determined by DSC

\begin{tabular}{|c|c|c|c|}
\hline Microbeads & $\mathbf{T}_{\mathbf{g}}\left({ }^{\circ} \mathbf{C}\right)$ & $\mathbf{T}_{\mathbf{m}}\left({ }^{\circ} \mathbf{C}\right)$ & $\Delta \mathbf{H}_{\mathbf{m}}(\mathbf{J} / \mathbf{g})^{\mathbf{a}}$ \\
\hline PHBHV & $2.0-3.7$ & 173 & 97 \\
\hline PHBHHx (6\%) & $1.9-2.3$ & 125 and $144^{\mathrm{b}}$ & 56 \\
\hline PHBHHx (11\%) & $-1.1--0.5$ & 109 and $137^{\mathrm{b}}$ & 40 \\
\hline PLA & $60-63$ & 147 & 22 \\
\hline
\end{tabular}

Values of melting enthalpy, $\Delta \mathrm{Hm}$, are given as raw data and not converted into crystalline content because of the absence of reference for a PHA with $100 \%$ crystallinity.

b Two melting peaks were detected, one corresponding to PHB and the second one to HHx unit.

Thus, it can be concluded from these DSC analyses, that the elaboration process has no impact on the crystallization process of the PHA bead, as revealed by the SEM and AFM images. From these data, it appears that the most crystalline bead is the PHBHV sample. A difference in crystalline content can also be observed between the two PHBHHx samples, with the most crystalline bead being the $6 \%$ in $\mathrm{HHx}$ content. This data emphasizes the role of the chemical nature of lateral chain (HV vs $\mathrm{HHx}$ ) in the PHA structure and in the final properties of the polymer material. The lateral chain may play the role of a plasticizer. For example, it has been demonstrated that increasing the fraction of HV monomers in PHBHV samples render the materials more ductible and less brittle, associated with a decrease in the melting and glass temperature proportionally [60]. Similarly, it has been shown that, increasing the 
percentage of $\mathrm{HHx}$ from 7 to $18 \%$ results in a decrease in the crystallization rate and suppression of the spherulitic growth rate [24].

FTIR spectroscopy was performed in order to evaluate the surface crystallinity of the different beads. This technique is complementary with the DSC technique that give an overall estimation of the crystallinity, independently of the structural organization of the polymer within the bead and from the center of mass. FTIR, owing to the penetration depth of the IR beam of a about one micron [61], can be directly applied on the beads in contact with the ATR crystal and thus may give access to the polymer organization on its periphery, or close to it.

FTIR spectroscopy analysis were performed in order to get access to the surface crystallinity of the different beads. This technique is highly complementary with the DSC technique that give an overall estimation of the crystallinity, independently of the structural organization of the polymer within the bead and from the center of mass. FTIR is sensitive to the polymer organization on its periphery and within a thickness of a one micron approximatively. FTIR spectra of PHA microbeads are presented on

\section{Figure 4.}

Figure 4 represents an IR spectrum of the PHA microbeads and reveals the different bands of interest for this polymer. The bands at 1230, 1380 and $1724 \mathrm{~cm}^{-1}$ are assigned to the crystalline part of the PHA sample whereas those at 1186 and $1741 \mathrm{~cm}^{-1}$ are representative of the amorphous part (see Table 5A). By comparing the intensities ratio of some of the characteristic bands of PHA, some authors were able to evaluate a crystallinity index and established a correlation between FTIR and DSC measurements $[62,63]$. In the work of Xu et al. [62], the crystallinity index was calculated as the ratio of the crystalline band at $1380 \mathrm{~cm}^{-1}$, assigned as the conformational band of helical chains in the crystalline phase, over the amorphous reference peak at $1453 \mathrm{~cm}^{-1}$, assigned as methyl $\left(\mathrm{CH}_{3}\right)$ or methylene $\left(\mathrm{CH}_{2}\right)$ deformations [63]. In other studies, the crystallinity index of PHA samples was also evaluated by calculating the ratio of the absorbance peak at $1227 \mathrm{~cm}^{-1}$ over the absorbance peak at $1184 \mathrm{~cm}^{-1}$ [61], between the absorbance peak at $1724 \mathrm{~cm}^{-1}$ over the absorbance peak $1453 \mathrm{~cm}^{-1}$ [63], or between the absorbance peaks at $1380 \mathrm{~cm}^{-1}$ over the amorphous band at $1186 \mathrm{~cm}^{-1}$ [64]. 
Intensities of these ratio are reported in the Table 5B. The ratios of the crystalline peaks on to the amorphous peaks gives the highest ratio for the PHBHV bead, followed by the PHBHHx at $6 \%$ and $11 \%$ respectively. These results are in good agreements with the previous DSC results and confirms that the crystallinity on the surface of the particles is well correlated with the crystallinity content of the particles.

The roughness parameter is also in good correlation with this finding.

Table 5A: identification of the representative FTIR peak for the different PHA samples

\begin{tabular}{|c|c|c|}
\hline Frequency $\left(\mathrm{cm}^{-1}\right)$ & Description & References \\
\hline 1741 & stretching vibration of the amorphous carbonyl group & $\begin{array}{c}{[61-63,65,} \\
66]\end{array}$ \\
\hline 1724 & stretching vibration of the crystalline carbonyl group & $\begin{array}{c}{[61-63,65,} \\
66]\end{array}$ \\
\hline 1453 & $\begin{array}{c}\text { methyl }\left(\mathrm{CH}_{3}\right) \text { or methylene }\left(\mathrm{CH}_{2}\right) \text { deformations in the } \\
\text { amorphous phase }\end{array}$ & [63] \\
\hline 1380 & symmetric wagging of $\mathrm{CH}_{3}$ in the crystalline phase & [61-63] \\
\hline $1227-1230$ & $\begin{array}{l}\text { absorption of helical ( } \alpha \text {-type) crystals (C-O-C } \\
\text { stretching modes of the crystalline components) }\end{array}$ & {$[61,62,67]$} \\
\hline $1184-1186$ & asymmetric C-O-C stretches (amorphous phase) & [61-63] \\
\hline
\end{tabular}

Table 5B: Comparison of the representative FTIR peak intensities ratios for the different PHA samples.

\begin{tabular}{|c|c|c|c|}
\hline Microbeads & $\frac{\boldsymbol{I}_{\mathbf{1 3 8 0}}}{\boldsymbol{I}_{\mathbf{1 1 8 6}}}$ & $\frac{\boldsymbol{I}_{\mathbf{1 2 3 0}}}{\boldsymbol{I}_{\mathbf{1 4 5 3}}}$ & $\frac{\boldsymbol{I}_{\mathbf{1 2 2 7}}}{\boldsymbol{I}_{\mathbf{1 1 8 4}}}$ \\
\hline PHBHV & 0.52 & 2.6 & 0.53 \\
\hline PHBHHx (6\%) & 0.27 & 1.21 & 0.28 \\
\hline PHBHHx (11\%) & 0.21 & 0.87 & 0.15 \\
\hline
\end{tabular}

Nanoindentation measurements on the microbeads, with the MTS equipment, required their immobilization by an inclusion in an epoxy resin. However, due to their size and color, they were not clearly distinguishable on the surface of the resin. Furthermore, with an epoxy resin with a similar 
identifying correctly the polymer beads among the resin. Thus, nanoindentation test have been performed here directly on the pellets, even if a direct comparison with the bead materials should be cautious. In parallel to this nanoindentation experiments, PFQNM were realized directly on the top of the microbeads. With the AFM, it is easier to place the AFM tip on a top a bead to measure its mechanical properties locally.

Table 6 reports the values of the modulus for the different polymers pellets, as measured by nanoindentation. At first, the Young's modulus for PLA is found to be around $5.5 \mathrm{GPa}$, in good agreement with the literature value [68]. For the PHA samples, the two PHBHHx samples give the lowest Young's modulus as compared to the PHBHV. For the PHBHV polymer, a Young's modulus of 7.5 GPa has been found, similar to the measurements of Chick et al on injected PHBHV polymer [47].

The highest modulus found for the PHBHV sample can be related with its high crystalline content. In contrast, the PHBHHX samples shows the lowest Young's modulus, the 11\% content in HHX monomer having the lowest modulus. These results are in good agreement with the recent work of Voyiadjis et al. [69], who studied the mechanical properties of PEEK semi-crystalline polymers. By varying the cooling rate of their sample, they vary the degree of crystallinity of their samples and observed a softer response of the amorphous polymer part as compared to the crystalline regions.

Table 6: Modulus and hardness of the different polymer materials (pellets) as measured by nanoindentation

\begin{tabular}{|c|c|c|}
\hline Microbeads & Modulus (GPa) & Hardness (GPa) \\
\hline PHBHV & $6.9 \pm 0.8$ & $0.26 \pm 0.06$ \\
\hline PHBHHx 6\% & $2.8 \pm 0.5$ & $0.10 \pm 0.02$ \\
\hline PHBHHx 11\% & $1.7 \pm 0.2$ & $0.07 \pm 0.01$ \\
\hline PLA & $5.6 \pm 0.2$ & $0.31 \pm 0.02$ \\
\hline
\end{tabular}

Figure 5 represents the distribution in the indentation modulus for the different beads as measured by PFQNM. Results obtained are consistent with the moduli obtained by nanoindentation. One should observe nonetheless a slight increase in the modulus of the PHBHHx beads, measured by PFQNM as compared to the modulus of the pellets, obtained by nanoindentation. However, precautions should be 
taken for an accurate determination of the modulus by PFQNM. At first, the calibration of the tip radius was performed on fairly flat Polystyrene film with a low roughness in comparison with the rough surface topographies of the different beads. Tip convolution effect is likely to occur, especially on rough surfaces as it is the case here and may result in different contact area which can affect the indentation modulus calculated from the force curve analysis. It has also been recently postulated that PFQNM experiments may provide slightly larger modulus as compared to other mechanical techniques, since the force curve may be partially impacted by the presence of adsorbed water that may increase the adhesion force between the tip and sample [70]. Nonetheless, the variation in the mechanical properties, as observed by the two techniques confirms that the bead present different mechanical properties, in correlation with their crystalline content and their chemical structure. Furthermore, it was found that the mechanical properties of the so-formed microparticles, following the described fabrication process, are comparable with the initial properties of the polymer pellets.

Finally, the hardness of the different samples was extracted from the nanoindentation measurements, as described by Oliver and Pharr [56]. The results, presented in Table 6, reveal that both PHBHHx samples have the lowest hardness in contrast with the PHBHV and PLA samples with a hardness around 0.3 GPa. Despite the PLA sample, the trend for PHA samples is also following the crystalline state of the different samples, the more crystalline being the more tough. For the PLA sample, which is less crystalline than the PHA sample, the mechanical properties can be correlated to its high glass transition in comparison with the PHA samples. It has been reported that the intrinsic stiffness of glassy polymers below the $\mathrm{T}_{\mathrm{g}}$ may leads to microhardness values larger than those obtained for semi-crystalline polymers [71].

\subsection{Stability in aqueous medium and biodegradability in marine environment}

The stability of these particles in aqueous medium, with various conditions to mimic ageing conditions for cosmetic products (room temperature, room temperature in the presence of light and accelerated ageing at $45{ }^{\circ} \mathrm{C}$ ) was verified by measuring the $\mathrm{pH}$ of the solution during a period of 3 -months storage. The comparison between the PHA and PLA microbeads allows to observe different trends. On the one 
hand, the $\mathrm{pH}$ variation for the solution containing the PHA microbeads was only slightly decreasing, with a $\mathrm{pH}$ variation inferior to $1 \mathrm{pH}$ unit. For example, after 3 months at room temperature, $\mathrm{pH}$ of 3.9 for PHBHV, 3.7 for PHBHHx (6\%) and 3.8 for PHBHHx (11\%) were measured respectively in contrast with a starting $\mathrm{pH}$ of 4.2. Similar results were obtained when the PHA microbeads suspension was exposed to the $45^{\circ} \mathrm{C}$ thermostated aqueous solution ( $\mathrm{pH}$ of 3.8, 3.6 and 3.7 for PHBHV, PHBHHx (6\%) and PHBHHx (11\%) respectively) and a more pronounced decreased of the $\mathrm{pH}$, but still less than $1 \mathrm{pH}$ unit, was recorded for the suspension in the solution at room temperature and exposed to light $(\mathrm{pH}$ of 3.5, 3.6 and 3.6 for PHBHV, PHBHHx (6\%) and PHBHHx (11\%) respectively).

On the other hand, the $\mathrm{pH}$ of the PLA suspension is decreasing of $1 \mathrm{pH}$ unit for the normal aqueous solution conditions and aqueous solution plus light exposure conditions (from a $\mathrm{pH}=4.4$ down to a $\mathrm{pH}$ $=3.4$ ) and by $2 \mathrm{pH}$ unit for the $45^{\circ} \mathrm{C}$ aqueous solution conditions (from $\mathrm{pH}=4.4$ to $\mathrm{pH}=2.4$ ). The acidification of the PLA suspension can be correlated with a degradation of the polymer particles, showing that the PHA microparticles are less degradable and more sable under these conditions than PLA in aqueous medium.

The Figure 6 shows the biodegradability of the different microbeads in seawater. The biodegradation has been performed on marine environment (seawater + sediments) at $25^{\circ} \mathrm{C}$, according to the NF EN ISO 19679 standard.

As expected, PLA microbeads are poorly biodegradable in these conditions since their biodegradation degree is only about $20 \%$ after 250 incubation days. It has been previously demonstrated that PLA is relatively stable, due to its glassy state at $25^{\circ} \mathrm{C}$, as long as the medium temperature does not exceed the PLA glass transition temperature, i.e. about $55^{\circ} \mathrm{C}[72]$.

Concerning the PHA series, significant differences on the biodegradability can be noted depending on the chemical PHA structure. The PHBHV turns out to be the most biodegradable as its biodegradability percentage reaches to $90 \%$ after 250 days of immersion. For the PHBHHx, the composition of monomer units also influences the biodegradability since the PHBHHx with $11 \%$ in $\mathrm{HHx}$ biodegrades faster than the PHBHHx with $6 \%$ in HHx. The biodegradation rate is $80 \%$ for the first one and $62 \%$ for the second 
one. It is very interesting to note in the Figure 6 that all these PHA present a biodegradability greater than or close to that of the cellulose which is considered as a reference in terms of biodegradability. The beginning of the biodegradation is even faster for the 3 PHA compared to the cellulose.

This spectacular PHA biodegradability is explained the action of some marine microorganisms such as bacteria which excrete extracellular PHA degrading enzymes, i.e. PHA depolymerases, that hydrolyze water-insoluble PHA chains into water-soluble forms [73]. The resulting products are finally metabolized into the cells and utilized as nutriments [57]. At this temperature, the microbead degradation is therefore managed by an enzymatic degradation which is a heterogeneous surface reaction. Previous studies have revealed the presence of two PHA degradation mechanisms occurring in parallel (enzymatic degradation and chain scission by hydrolysis) but the enzymatic degradation is largely predominant at $25^{\circ} \mathrm{C}$ in marine ageing conditions [72]. This process, whatever the sample shape, takes place in the presence of PHA depolymerase involving two steps: the first step involves the adsorption of the enzymes on the surface by the binding domain of the enzymes and the second step involves the enzymatic cleavage of polymer chains by the active sites of the enzymes [74].

The slight differences in terms of biodegradation between the 3 PHA studied are more complicated to explain since the biodegradation is a combination of physical, chemical and biological phenomena leading to the material dissolution by enzymatic action of microorganisms. More experiments are needed in order to understand the role of the extrinsic (correlated to the medium) and intrinsic (relative to the polymer) parameters influencing the biodegradation process. It might be relevant to identity and quantify the microorganism population which specifically colonizes the microbeads surface during the test [75]. The diversity of microorganisms associated with these different stages of biodegradation is not yet characterized but this is being further explored in order to better understand the mechanisms. Likewise, the surface morphology of the different PHA has also to be studied in order to correlate the surface properties with the colonization and then the biodegradation. In this study, the PHBHV with $3 \%$ in HV is the most biodegradable while being the most crystalline compared to the 2 other PHBHHx. This could a priori constitute a surprising result even if some bibliographic data show that the substrate binding domain of the enzyme is capable to bind to the crystalline PHA material. PHA depolymerase being an 
enzyme made up of a catalytic domain and a substrate-binding domain, both these domains are connected by a linker domain. Subsequently, the catalytic domain starts to cleave the single crystals which can be enzymatically hydrolyzed [18]. Other parameters relative to PHA will have to be explored as the hydrophilic/hydrophobic balance of the surface as well as the surface porosity. Understanding the mechanism of PHA degradation and the factors that affect its degradation will help the researcher in designing suitable material for the specific needs.

\section{Conclusion}

The emulsion-evaporation method allowed the preparation of spherical micrometer PHA beads with tunable materials properties, surface morphologies and related degradation behavior. Using different chemical PHA structures, we showed that the different beads have properties and surface morphologies that are governed by the crystalline organization of the polymer chains within the beads, thus able to provide suitable abrasive and mechanical properties for cosmetics applications. Since pollution of aquatics systems by microplastics should be stopped, the degradation behavior of these PHA microbeads were further tested in marine environment. The degradation experiments reveal that the degradation rate and kinetic were even faster than those of cellulose polymer considered as the most biodegradable polymer materials and also suggest the crucial role of the crystalline content in the degradation process of PHA beads. Very interestingly, these PHA particles are stable in the aqueous media commonly used in cosmetics while being rapidly biodegradable in the marine environment. By combining these two behaviors, they thus offer ideal characteristics for the development of microbeads in cosmetics. In addition, tuning the surface morphologies and biodegradable properties of PHA beads, by using different PHA structures, this provides an effective and promising approach to replace conventional plastic beads from formulation in cosmetic products.

\section{Acknowledgments}

The authors would like to thank the Bretagne region for its financial support in this collaborative project called BIOBILLES. The authors are also pleased to express their grateful acknowledgments to Charles- 
421 for technological innovation) for their contribution to this research program.

\section{References}

[1] N.B. Hartmann, T. Hüffer, R.C. Thompson, M. Hassellöv, A. Verschoor, A.E. Daugaard, S. Rist, T. We Speaking the Same Language? Recommendations for a Definition and Categorization Framework for Plastic Debris, Environmental Science \& Technology 53(3) (2019) 1039-1047.

[2] Q. Sun, S.-Y. Ren, H.-G. Ni, Incidence of microplastics in personal care products: An appreciable part of plastic pollution, Science of The Total Environment 742 (2020) 140218.

[3] T. Gouin, J. Avalos, I. Brunning, K. Brzuska, J. de Graaf, J. Kaumanns, T. Koning, M. Meyberg, K. Rettinger, H. Schlatter, Use of micro-plastic beads in cosmetic products in Europe and their estimated emissions to the North Sea environment, SOFW J 141(4) (2015) 40-46.

[4] A.S. Tagg, J.A. Ivar do Sul, Is this your glitter? An overlooked but potentially environmentallyvaluable microplastic, Marine Pollution Bulletin 146 (2019) 50-53.

[5] S.M. Praveena, S.N.M. Shaifuddin, S. Akizuki, Exploration of microplastics from personal care and cosmetic products and its estimated emissions to marine environment: An evidence from Malaysia, Marine Pollution Bulletin 136 (2018) 135-140.

[6] K. Lei, F. Qiao, Q. Liu, Z. Wei, H. Qi, S. Cui, X. Yue, Y. Deng, L. An, Microplastics releasing from personal care and cosmetic products in China, Marine Pollution Bulletin 123(1) (2017) 122-126.

[7] I.E. Napper, A. Bakir, S.J. Rowland, R.C. Thompson, Characterisation, quantity and sorptive properties of microplastics extracted from cosmetics, Marine Pollution Bulletin 99(1) (2015) 178-185.

[8] V. Godoy, M.A. Martín-Lara, M. Calero, G. Blázquez, Physical-chemical characterization of microplastics present in some exfoliating products from Spain, Marine Pollution Bulletin 139 (2019) 91-99.

[9] A. Piotrowska, O. Czerwińska-Ledwig, M. Serdiuk, K. Serdiuk, W. Pilch, Composition of scrubtype cosmetics from the perspective of product ecology and microplastic content, Toxicology Environmental Health Sciences (2020) 1-7.

[10] E. Kentin, H. Kaarto, An EU ban on microplastics in cosmetic products and the right to regulate, Review of European, Comparative \& International Environmental Law 27(3) (2018) 254-266.

[11] L. Anagnosti, A. Varvaresou, P. Pavlou, E. Protopapa, V. Carayanni, Worldwide actions against plastic pollution from microbeads and microplastics in cosmetics focusing on European policies. Has the issue been handled effectively?, Marine Pollution Bulletin 162 (2021) 111883.

[12] C. Guerranti, T. Martellini, G. Perra, C. Scopetani, A. Cincinelli, Microplastics in cosmetics: Environmental issues and needs for global bans, Environmental Toxicology and Pharmacology 68 (2019) 75-79.

[13] R.Z. Habib, M.M. Salim Abdoon, R.M. Al Meqbaali, F. Ghebremedhin, M. Elkashlan, W.F. Kittaneh, N. Cherupurakal, A.-H.I. Mourad, T. Thiemann, R. Al Kindi, Analysis of microbeads in cosmetic products in the United Arab Emirates, Environmental Pollution 258 (2020) 113831.

[14] W. Prus, J. Kozlowska, The influence of new polymeric microbeads in peeling products on skin condition, Molecular Crystals and Liquid Crystals 671(1) (2018) 140-147.

[15] L. da Silva Dutra, T. de Souza Belan Costa, V.T.V. Lobo, T.F. Paiva, M. de Souza Nele, J.C. Pinto, Preparation of Polymer Microparticles Through Non-aqueous Suspension Polycondensations: Part IIIDegradation of PBS Microparticles in Different Aqueous Environments, Journal of Polymers and the Environment 27(1) (2019) 176-188.

[16] Y.-K. Hsieh, P.-H. Hung, C.-W. Huang, K.-C. Chuang, J. Wang, Study on the degradation of biodegradable poly (glycerol maleate) (PGM) microbeads, Polymer Degradation and Stability 179 (2020) 109223.

[17] K. Rettinger, B. Huber, Microplastic Particles in Cosmetic Products - Impact on the Environment?, SOFW J (Proceedings of the 49th Essener Conference) (2016) 28-32. 
[18] K. Sudesh, H. Abe, Y. Doi, Synthesis, structure and properties of polyhydroxyalkanoates:

[19] Z.A. Raza, S. Abid, I.M. Banat, Polyhydroxyalkanoates: Characteristics, production, recent developments and applications, International Biodeterioration \& Biodegradation 126 (2018) 45-56.

[20] P. Lemechko, M. Le Fellic, S. Bruzaud, Production of poly(3-hydroxybutyrate-co-3hydroxyvalerate) using agro-industrial effluents with tunable proportion of 3-hydroxyvalerate monomer units, International Journal of Biological Macromolecules 128 (2019) 429-434.

[21] S. Modi, K. Koelling, Y. Vodovotz, Assessment of PHB with varying hydroxyvalerate content for potential packaging applications, European Polymer Journal 47(2) (2011) 179-186.

[22] W. Zhao, G.-Q. Chen, Production and characterization of terpolyester poly(3-hydroxybutyrate-co3-hydroxyvalerate-co-3-hydroxyhexanoate) by recombinant Aeromonas hydrophila 4AK4 harboring genes phaAB, Process Biochemistry 42(9) (2007) 1342-1347.

[23] G.-Q. Chen, Q. Wu, The application of polyhydroxyalkanoates as tissue engineering materials, Biomaterials 26(33) (2005) 6565-6578.

[24] H. Cai, Z. Qiu, Effect of comonomer content on the crystallization kinetics and morphology of biodegradable poly(3-hydroxybutyrate-co-3-hydroxyhexanoate), Physical Chemistry Chemical Physics 11(41) (2009) 9569-9577.

[25] Y. Doi, S. Kitamura, H.J.M. Abe, Microbial synthesis and characterization of poly (3hydroxybutyrate-co-3-hydroxyhexanoate), 28(14) (1995) 4822-4828.

[26] H. Alata, T. Aoyama, Y. Inoue, Effect of Aging on the Mechanical Properties of Poly(3hydroxybutyrate-co-3-hydroxyhexanoate), Macromolecules 40(13) (2007) 4546-4551.

[27] A. Tsui, C.W. Frank, Impact of Processing Temperature and Composition on Foaming of Biodegradable Poly(hydroxyalkanoate) Blends, Industrial \& Engineering Chemistry Research 53(41) (2014) 15896-15908.

[28] X.-H. Qu, Q. Wu, J. Liang, B. Zou, G.-Q. Chen, Effect of 3-hydroxyhexanoate content in poly(3hydroxybutyrate-co-3-hydroxyhexanoate) on in vitro growth and differentiation of smooth muscle cells, Biomaterials 27(15) (2006) 2944-2950.

[29] V.D. Alves, C.A.V. Torres, F. Freitas, Bacterial polymers as materials for the development of micro/nanoparticles, International Journal of Polymeric Materials and Polymeric Biomaterials 65(5) (2016) 211-224.

[30] S.L. Duraikkannu, R. Castro-Muñoz, A. Figoli, A review on phase-inversion technique-based polymer microsphere fabrication, Colloid and Interface Science Communications 40 (2021) 100329.

[31] Y. Farrag, W. Ide, B. Montero, M. Rico, S. Rodríguez-Llamazares, L. Barral, R. Bouza, Preparation of starch nanoparticles loaded with quercetin using nanoprecipitation technique, International Journal of Biological Macromolecules 114 (2018) 426-433.

[32] A. Rodríguez-Contreras, C. Canal, M. Calafell-Monfort, M.-P. Ginebra, G. Julio-Moran, M.-S. Marqués-Calvo, Methods for the preparation of doxycycline-loaded phb micro- and nano-spheres, European Polymer Journal 49(11) (2013) 3501-3511.

[33] R. Bouza, M. del Mar Castro, S. Dopico-García, M. Victoria González-Rodríguez, L.F. Barral, B. Bittmann, Polylactic acid and poly(3-hydroxybutyrate-co-3-hydroxyvalerate) nano and microparticles for packaging bioplastic composites, Polymer Bulletin 73(12) (2016) 3485-3502.

[34] S. Wohlfart, S. Gelperina, J. Kreuter, Transport of drugs across the blood-brain barrier by nanoparticles, Journal of Controlled Release 161(2) (2012) 264-273.

[35] J.L. Maia, M.H.A. Santana, M.I. Ré, The effect of some processing conditions on the characteristics of biodegradable microspheres obtained by an emulsion solvent evaporation process, Brazilian Journal of Chemical Engineering 21 (2004) 01-12.

[36] N.L. Zalloum, G. Albino de Souza, T.D. Martins, Single-Emulsion P(HB-HV) Microsphere Preparation Tuned by Copolymer Molar Mass and Additive Interaction, ACS Omega 4(5) (2019) 81228135.

[37] V. Deepak, S.b. Ram Kumar Pandian, K. Kalishwaralal, S. Gurunathan, Purification, immobilization, and characterization of nattokinase on PHB nanoparticles, Bioresource Technology 100(24) (2009) 6644-6646.

[38] G.A. Senhorini, S.F. Zawadzki, P.V. Farago, S.M.W. Zanin, F.A. Marques, Microparticles of poly(hydroxybutyrate-co-hydroxyvalerate) loaded with andiroba oil: Preparation and characterization, Materials Science and Engineering: C 32(5) (2012) 1121-1126. 
[39] P.A. Coimbra, H.C.D. Sousa, M.H. Gil, Preparation and characterization of flurbiprofen-loaded (2008) 170-178.

[40] Z. Teixeira, N. Durán, S.S. Guterres, Annatto Polymeric Microparticles: Natural Product Encapsulation by the Emulsion-Solvent Evaporation Method, Journal of Chemical Education 85(7) (2008) 946.

[41] W.-C. Hsieh, P.-K. Lin, L.-H. Lin, C.-F. Huang, Flow cytometry analysis using at the poly(3hydroxybutyrate-co-3-hydrovalerate) microspheres for drug delivery system, Journal of the Taiwan Institute of Chemical Engineers 44(5) (2013) 829-835.

[42] J. Chen, S.S. Davis, The release of diazepam from poly(hydroxybutyrate-hydroxyvalerate) microspheres, Journal of Microencapsulation 19(2) (2002) 191-201.

[43] N. Durán, M.A. Alvarenga, E.C. Da Silva, P.S. Melo, P.D. Marcato, Microencapsulation of antibiotic rifampicin in poly(3-hydroxybutyrate-co-3-hydroxyvalerate), Archives of Pharmacal Research 31(11) (2008) 1509-1516.

[44] D. Sendil, I. Gürsel, D. L. Wise, V. Hasırc1, Antibiotic release from biodegradable PHBV microparticles, Journal of Controlled Release 59(2) (1999) 207-217.

[45] J. Hui, X.J. Yu, Y. Zhang, F.Q. Hu, Characterization of anti-cancer drug materials loaded poly (3hydroxybutyrate-co-3-hydroxyhexanoate) microspheres for drug delivery system in biochemical material system, Advanced Materials Research, Trans Tech Publ, 2012, pp. 137-143.

[46] S. Cheng, Q. Wu, Y. Zhao, B. Zou, G.-Q. Chen, Effect of poly(hydroxybutyrate-cohydroxyhexanoate) microparticles on growth of murine fibroblast L929 cells, Polymer Degradation and Stability 91(12) (2006) 3191-3196.

[47] A. Chikh, A. Benhamida, M. Kaci, A. Bourmaud, S. Bruzaud, Recyclability assessment of poly(3hydroxybutyrate-co-3-hydroxyvalerate)/poly(butylene succinate) blends: Combined influence of sepiolite and compatibilizer, Polymer Degradation and Stability 142 (2017) 234-243.

[48] N. Dehouche, C. Idres, M. Kaci, I. Zembouai, S. Bruzaud, Effects of various surface treatments on Aloe Vera fibers used as reinforcement in poly(3-hydroxybutyrate-co-3-hydroxyhexanoate) (PHBHHx) biocomposites, Polymer Degradation and Stability 175 (2020) 109131.

[49] J. Vandewijngaarden, R. Wauters, M. Murariu, P. Dubois, R. Carleer, J. Yperman, J. D’Haen, B. Ruttens, S. Schreurs, N. Lepot, R. Peeters, M. Buntinx, Poly(3-hydroxybutyrate-co-3hydroxyhexanoate)/Organomodified Montmorillonite Nanocomposites for Potential Food Packaging Applications, Journal of Polymers and the Environment 24(2) (2016) 104-118.

[50] H. Sashiwa, R. Fukuda, T. Okura, S. Sato, A.J.M.d. Nakayama, Microbial degradation behavior in seawater of polyester blends containing poly (3-hydroxybutyrate-co-3-hydroxyhexanoate)(PHBHHx), Marine drugs 16(1) (2018) 34.

[51] I. Zembouai, M. Kaci, L. Zaidi, S. Bruzaud, Combined effects of Sepiolite and Cloisite 30B on morphology and properties of poly(3-hydroxybutyrate-co-3-hydroxyvalerate)/polylactide blends, Polymer Degradation and Stability 153 (2018) 47-52.

[52] T.R. Rigolin, L.C. Costa, T. Venâncio, B. Perlatti, S.H.P. Bettini, The effect of different peroxides on physical and chemical properties of poly(lactic acid) modified with maleic anhydride, Polymer 179 (2019) 121669.

[53] M. Wrona, M.J. Cran, C. Nerín, S.W. Bigger, Development and characterisation of HPMC films containing PLA nanoparticles loaded with green tea extract for food packaging applications, Carbohydrate Polymers 156 (2017) 108-117.

[54] I. Zembouai, M. Kaci, S. Bruzaud, L. Dumazert, A. Bourmaud, M. Mahlous, J.M. Lopez-Cuesta, Y. Grohens, Gamma irradiation effects on morphology and properties of PHBV/PLA blends in presence of compatibilizer and Cloisite 30B, Polymer Testing 49 (2016) 29-37.

[55] S. Bruzaud, A. Bourmaud, Thermal degradation and (nano)mechanical behavior of layered silicate reinforced poly(3-hydroxybutyrate-co-3-hydroxyvalerate) nanocomposites, Polymer Testing 26(5) (2007) 652-659.

[56] W.C. Oliver, G.M. Pharr, An improved technique for determining hardness and elastic modulus using load and displacement sensing indentation experiments, Journal of Materials Research 7(6) (1992) 1564-1583. 
[57] M. Deroiné, G. César, A. Le Duigou, P. Davies, S. Bruzaud, Natural Degradation and Biodegradation of Poly(3-Hydroxybutyrate-co-3-Hydroxyvalerate) in Liquid and Solid Marine Environments, Journal of Polymers and the Environment 23(4) (2015) 493-505.

[58] D.P. Pacheco, M.H. Amaral, R.L. Reis, A.P. Marques, V.M. Correlo, Development of an injectable PHBV microparticles-GG hydrogel hybrid system for regenerative medicine, International Journal of Pharmaceutics 478(1) (2015) 398-408.

[59] J. Bidone, A.P.P. Melo, G.C. Bazzo, F. Carmignan, M.S. Soldi, A.T.N. Pires, E. Lemos-Senna, Preparation and characterization of ibuprofen-loaded microspheres consisting of poly(3hydroxybutyrate) and methoxy poly (ethylene glycol)-b-poly (D,L-lactide) blends or poly(3hydroxybutyrate) and gelatin composites for controlled drug release, Materials Science and Engineering: C 29(2) (2009) 588-593.

[60] J.-W. You, H.-J. Chiu, W.-J. Shu, T.-M. Don, Influence of Hydroxyvalerate Content on the Crystallization Kinetics of Poly(hydroxybutyrate-co-hydroxyvalerate), Journal of Polymer Research 10(1) (2003) 47-54.

[61] Y. Kann, M. Shurgalin, R.K. Krishnaswamy, FTIR spectroscopy for analysis of crystallinity of poly(3-hydroxybutyrate-co-4 -hydroxybutyrate) polymers and its utilization in evaluation of aging, orientation and composition, Polymer Testing 40 (2014) 218-224.

[62] J. Xu, B.-H. Guo, R. Yang, Q. Wu, G.-Q. Chen, Z.-M. Zhang, In situ FTIR study on melting and crystallization of polyhydroxyalkanoates, Polymer 43(25) (2002) 6893-6899.

[63] S.-G. Hong, W.-M. Chen, The Attenuated Total Reflection Infrared Analysis of Surface Crystallinity of Polyhydroxyalkanoates e-Polymers 6(1) (2006).

[64] N. Vasanthan, D.R. Salem, FTIR spectroscopic characterization of structural changes in polyamide6 fibers during annealing and drawing, Journal of Polymer Science Part B: Polymer Physics 39(5) (2001) 536-547.

[65] M. Kansiz, A. Domínguez-Vidal, D. McNaughton, B. Lendl, Fourier-transform infrared (FTIR) spectroscopy for monitoring and determining the degree of crystallisation of polyhydroxyalkanoates (PHAs), Analytical and Bioanalytical Chemistry 388(5) (2007) 1207-1213.

[66] A. Padermshoke, H. Sato, Y. Katsumoto, S. Ekgasit, I. Noda, Y. Ozaki, Thermally induced phase transition of poly(3-hydroxybutyrate-co-3-hydroxyhexanoate) investigated by two-dimensional infrared correlation spectroscopy, Vibrational Spectroscopy 36(2) (2004) 241-249.

[67] J.S. Lim, K.-i. Park, G.S. Chung, J.H. Kim, Effect of composition ratio on the thermal and physical properties of semicrystalline PLA/PHB-HHx composites, Materials Science and Engineering: C 33(4) (2013) 2131-2137.

[68] D.D. Wright-Charlesworth, D.M. Miller, I. Miskioglu, J.A. King, Nanoindentation of injection molded PLA and self-reinforced composite PLA after in vitro conditioning for three months, $74 \mathrm{~A}(3)$ (2005) 388-396.

[69] G.Z. Voyiadjis, A. Samadi-Dooki, L. Malekmotiei, Nanoindentation of high performance semicrystalline polymers: A case study on PEEK, Polymer Testing 61 (2017) 57-64.

[70] I. Ovchinnikov, A. Vishnevskiy, D. Seregin, A. Rezvanov, D. Schneider, A. Sigov, K.A. Vorotilov, M. Baklanov, Evaluation of mechanical properties of porous OSG films by PFQNM AFM and benchmarking with traditional instrumentation, Langmuir 36(32) (2020) 9377-9387.

[71] A. Flores, F. Ania, F. Baltá-Calleja, From the glassy state to ordered polymer structures: A microhardness study, Polymer 50(3) (2009) 729-746.

[72] M. Deroiné, A. Le Duigou, Y.-M. Corre, P.-Y. Le Gac, P. Davies, G. César, S. Bruzaud, Accelerated ageing of polylactide in aqueous environments: Comparative study between distilled water and seawater, Polymer Degradation and Stability 108 (2014) 319-329.

[73] D. Jendrossek, O. Selchow, M. Hoppert, Poly(3-Hydroxybutyrate) Granules at the Early Stages of Formation Are Localized Close to the Cytoplasmic Membrane in Caryophanon latum, Applied and Environmental Microbiology 73(2) (2007) 586.

[74] K. Numata, H. Abe, Y. Doi, Enzymatic processes for biodegradation of poly(hydroxyalkanoate)s crystals, Canadian Journal of Chemistry 86(6) (2008) 471-483.

[75] C. Dussud, C. Hudec, M. George, P. Fabre, P. Higgs, S. Bruzaud, A.-M. Delort, B. Eyheraguibel, A.-L. Meistertzheim, J. Jacquin, J. Cheng, N. Callac, C. Odobel, S. Rabouille, J.-F. Ghiglione, Colonization of Non-biodegradable and Biodegradable Plastics by Marine Microorganisms, Frontiers in microbiology 9(1571) (2018). 


\section{Figures}

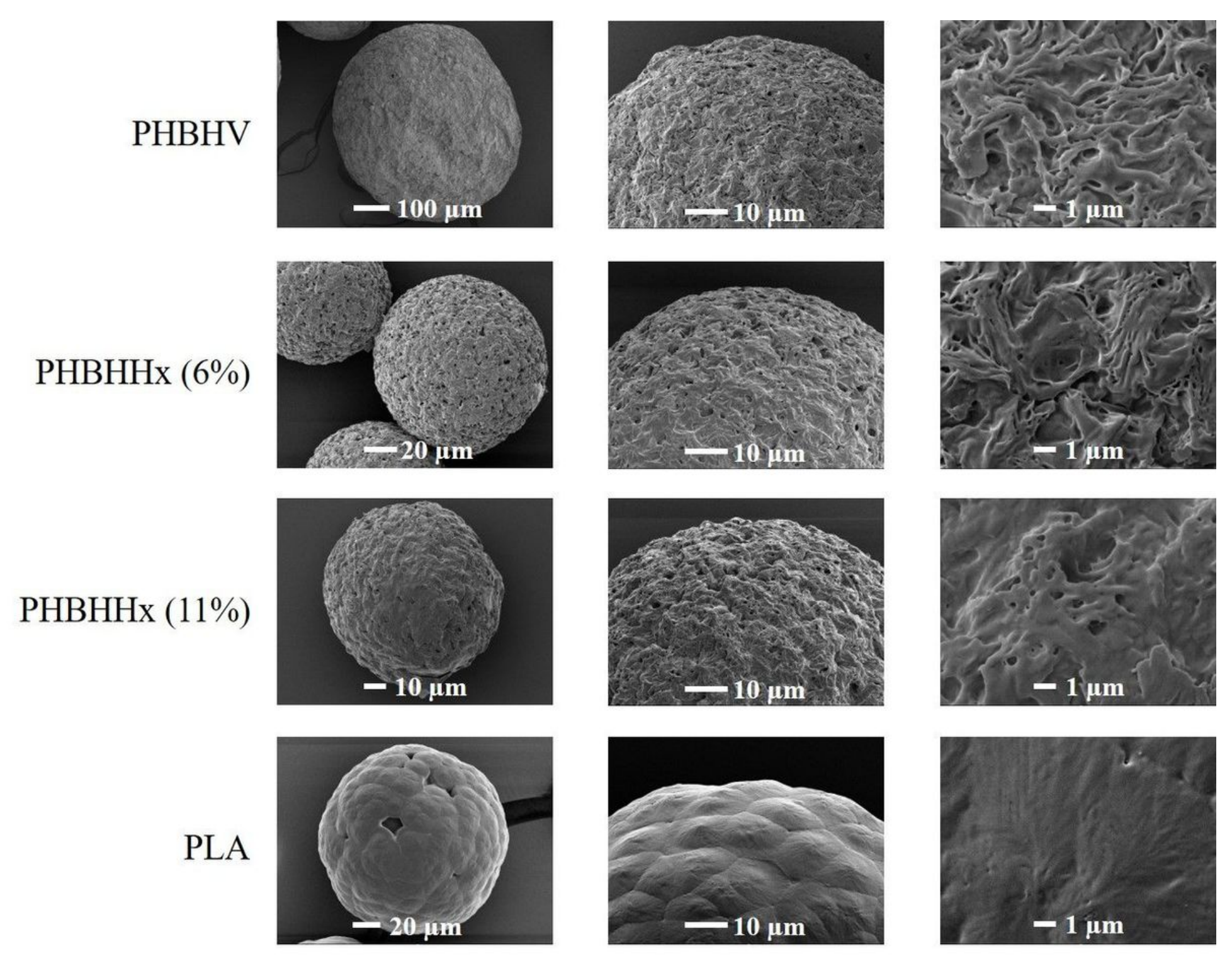

Figure 1

SEM images of the different microbeads are presented in Figure 1. 

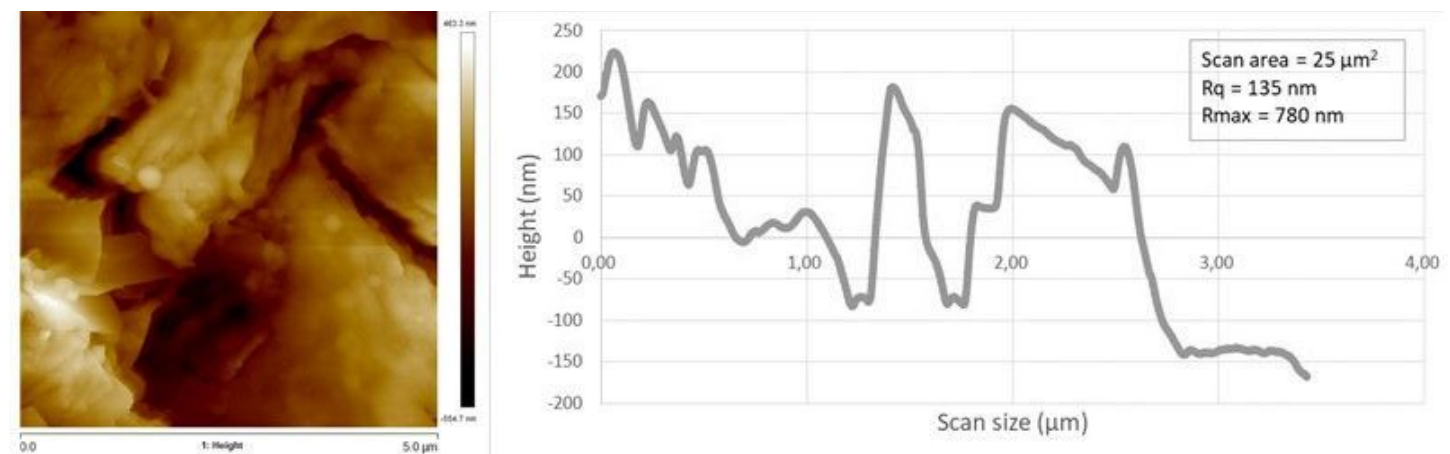

A) $\mathrm{PHBHV}$
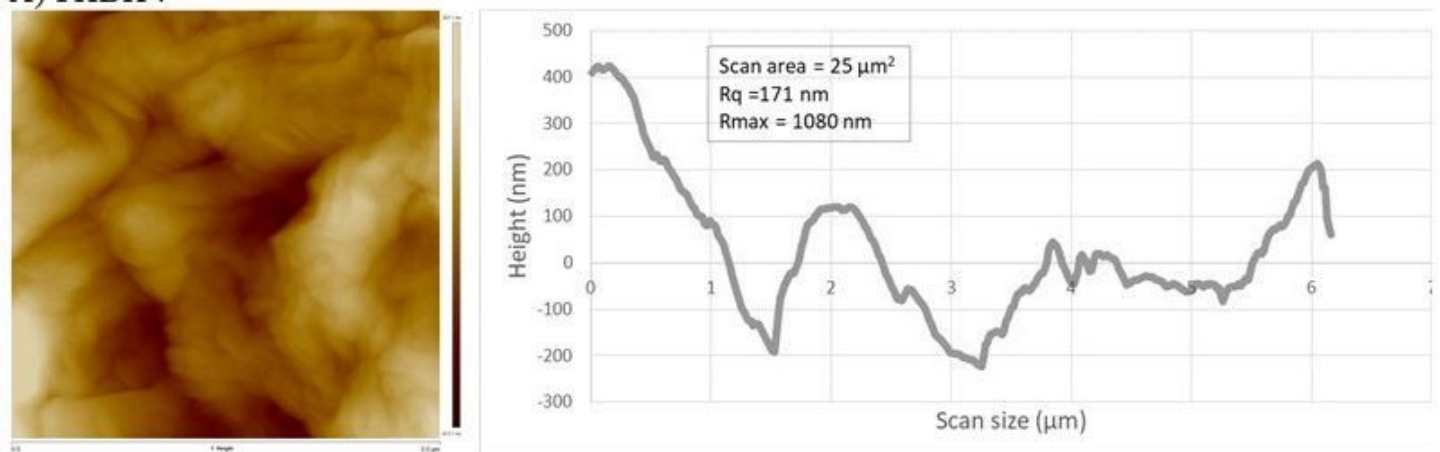

B) $\mathrm{PHBHHx}(6 \%)$
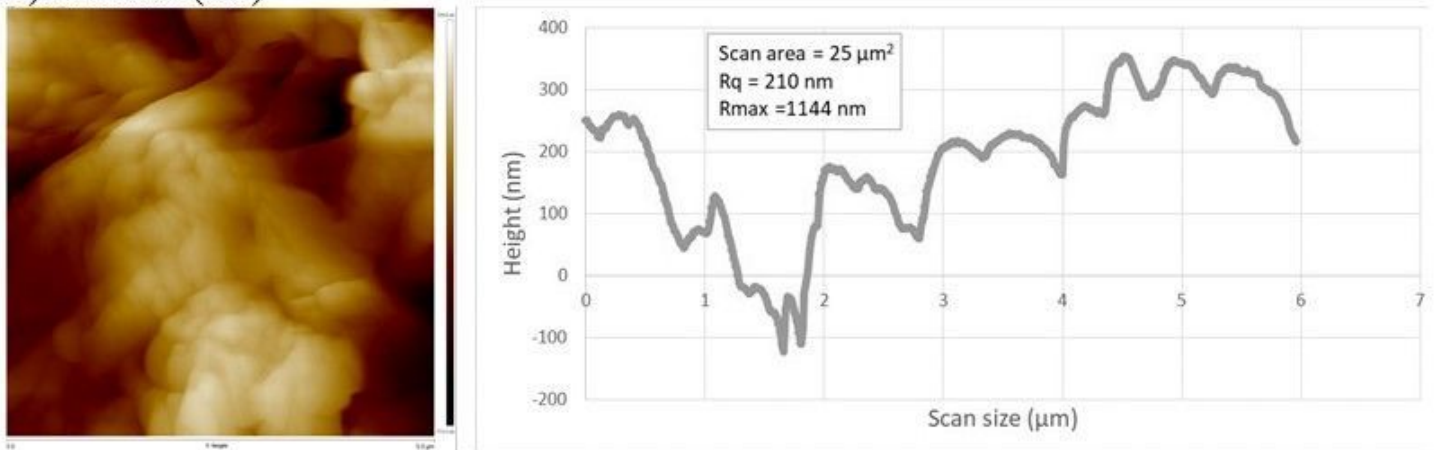

C) $\mathrm{PHBHHx}(11 \%)$
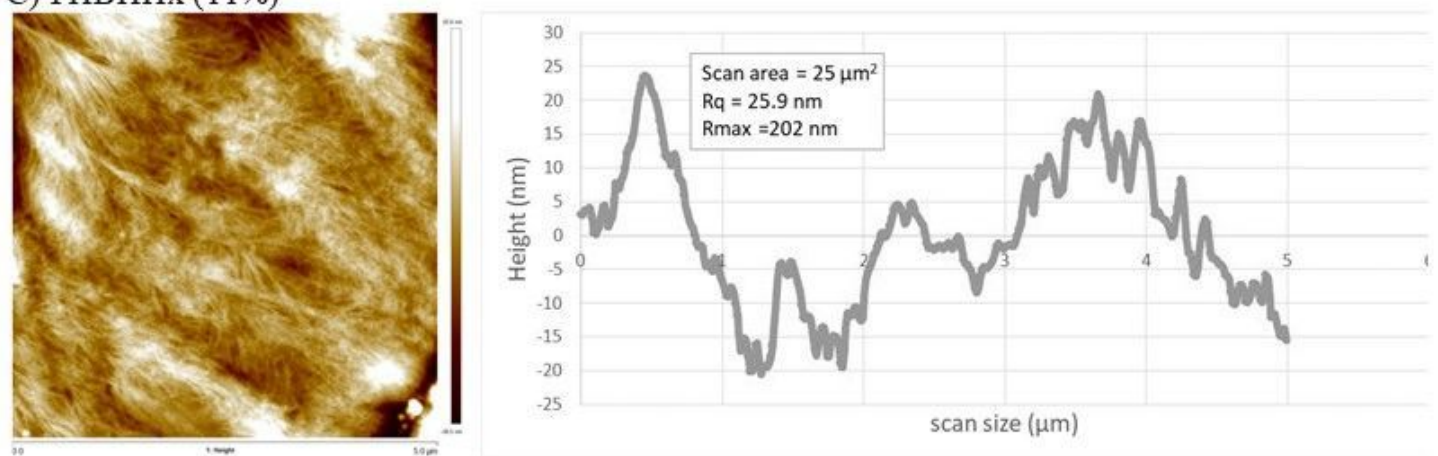

D) PLA

\section{Figure 2}

Figure 2 presents AFM images obtained of the top of the different beads and their corresponding surface analysis, confirming the smooth topography of the PLA beads and the important roughness of the PHA beads. 


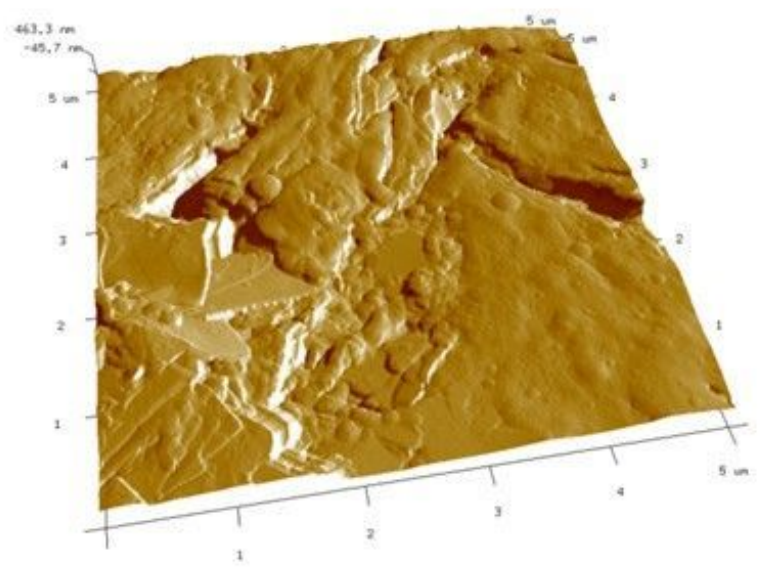

A) $\mathrm{PHBHV}$

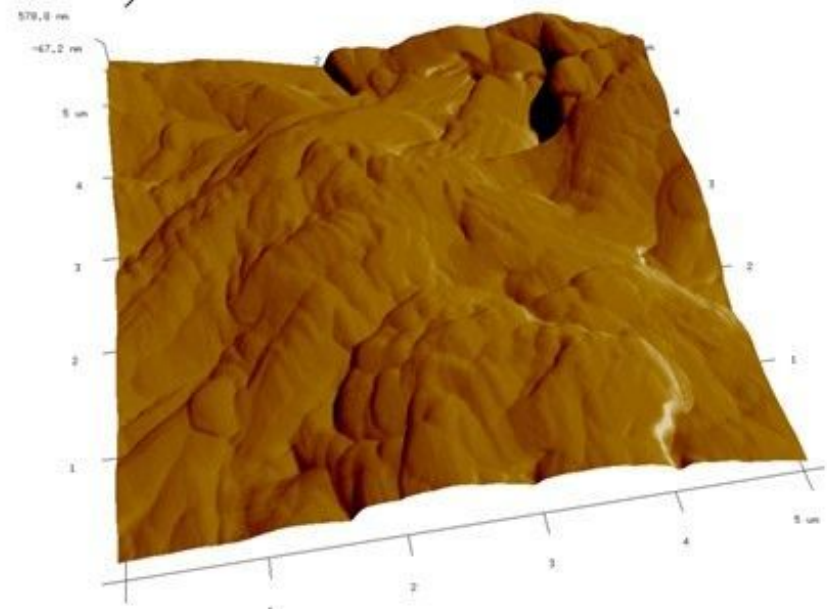

C) $\operatorname{PHBHHx}(11 \%)$

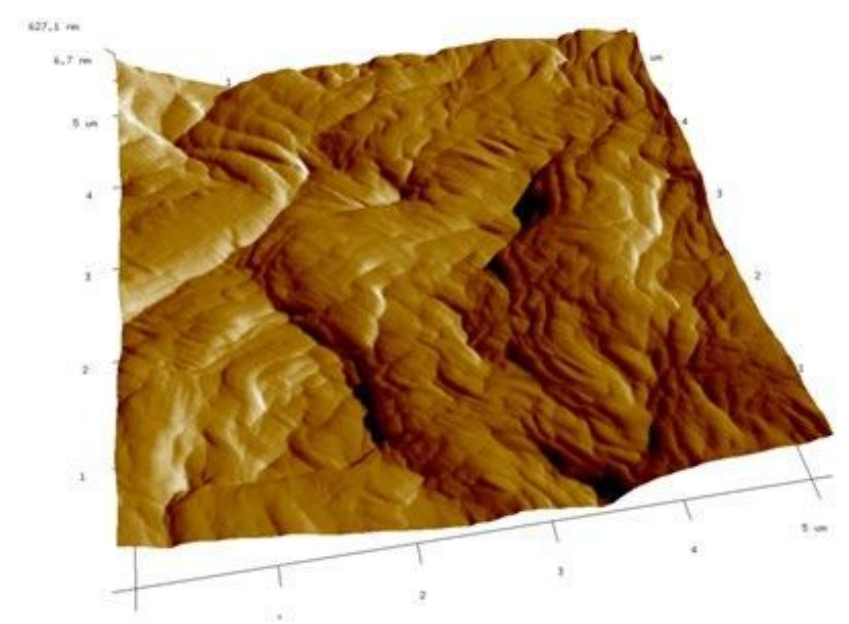

B) PHBHHx (6\%)

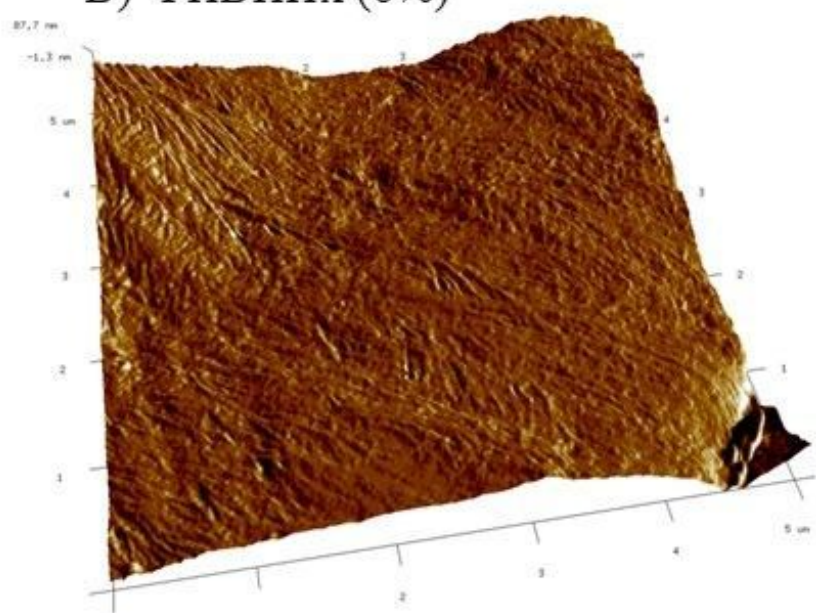

D) PLA

\section{Figure 3}

Microparticules of PHBHV, PHBHHx (6\% and 11\%) and PLA were elaborated by emulsification process. $\mathrm{PHBHV}$ was dissolved at $50 \mathrm{~g} \mathrm{~L}-1$ in chloroform under reflux conditions $\left(50^{\circ} \mathrm{C}\right), \mathrm{PHBHHx}$ and PLA were dissolved at the same concentration but in dichloromethane under reflux conditions $\left(40^{\circ} \mathrm{C}\right)$ during 24 hours. 


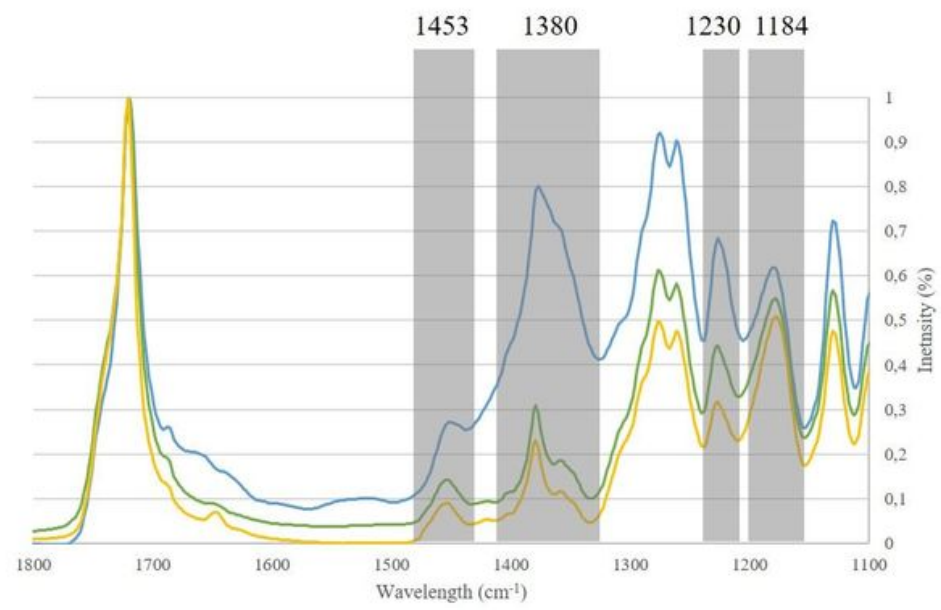

A

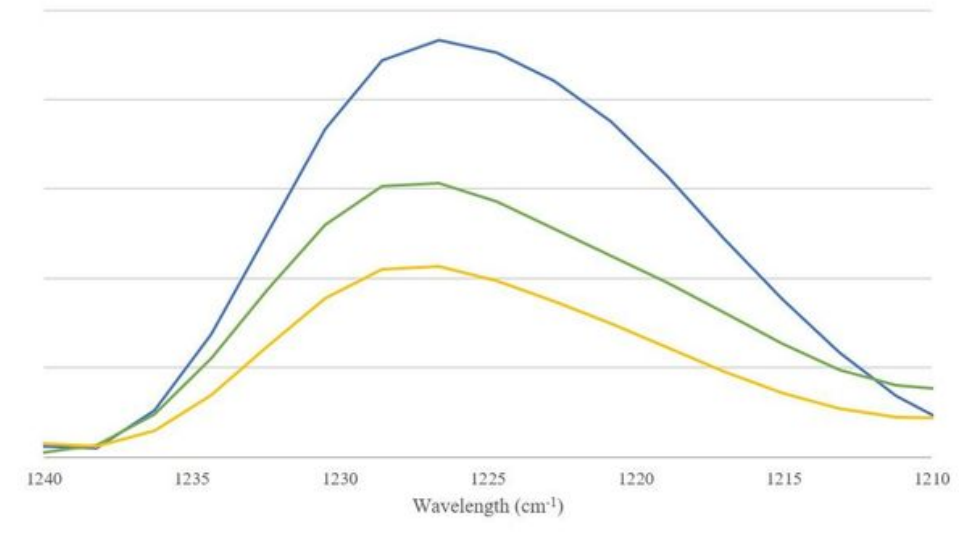

B

\section{Figure 4}

Figure 4 represents an IR spectrum of the PHA microbeads and reveals the different bands of interest for this polymer. 

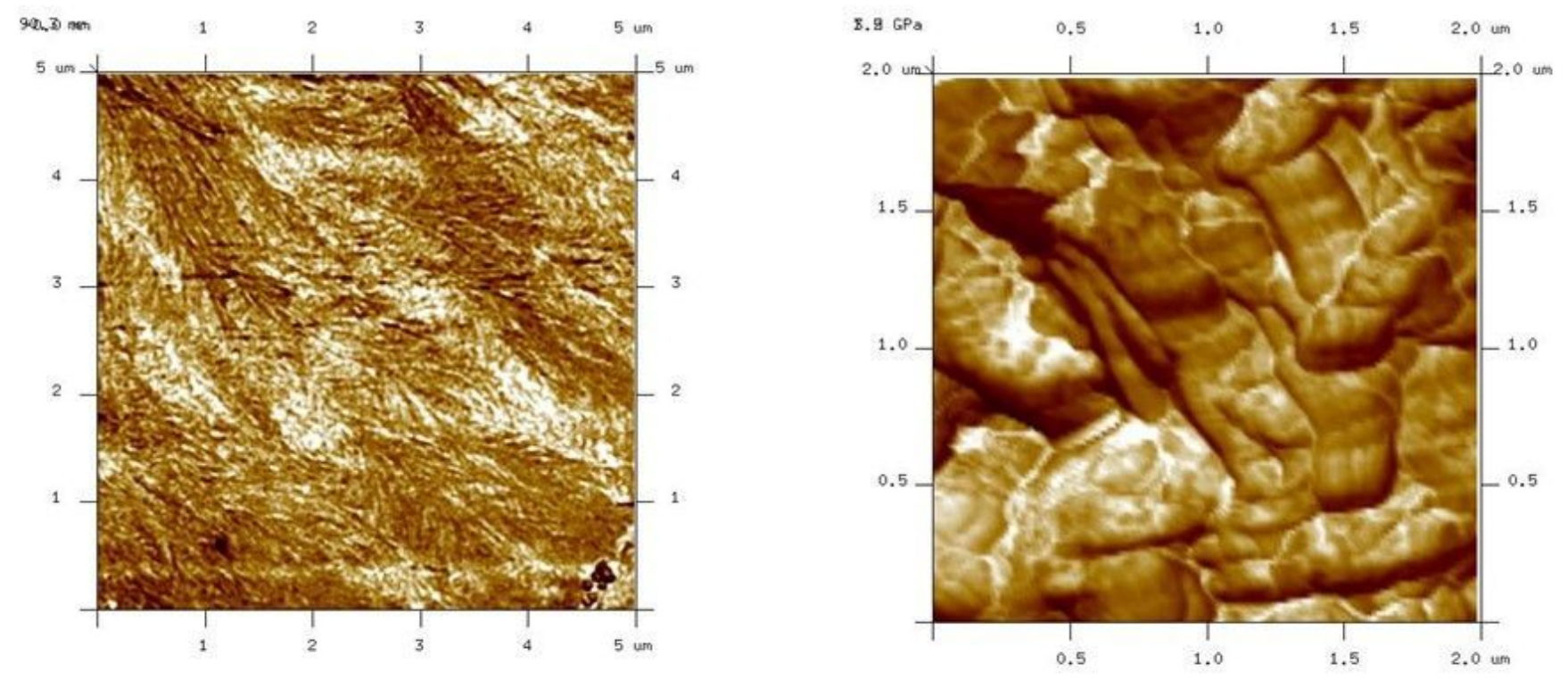

PLA, Indentation Modulus $=6.05 \pm 0.51 \mathrm{GPa}$

PHBHV, Indentation Modulus $=7.02 \pm 2.64 \mathrm{GPa}$
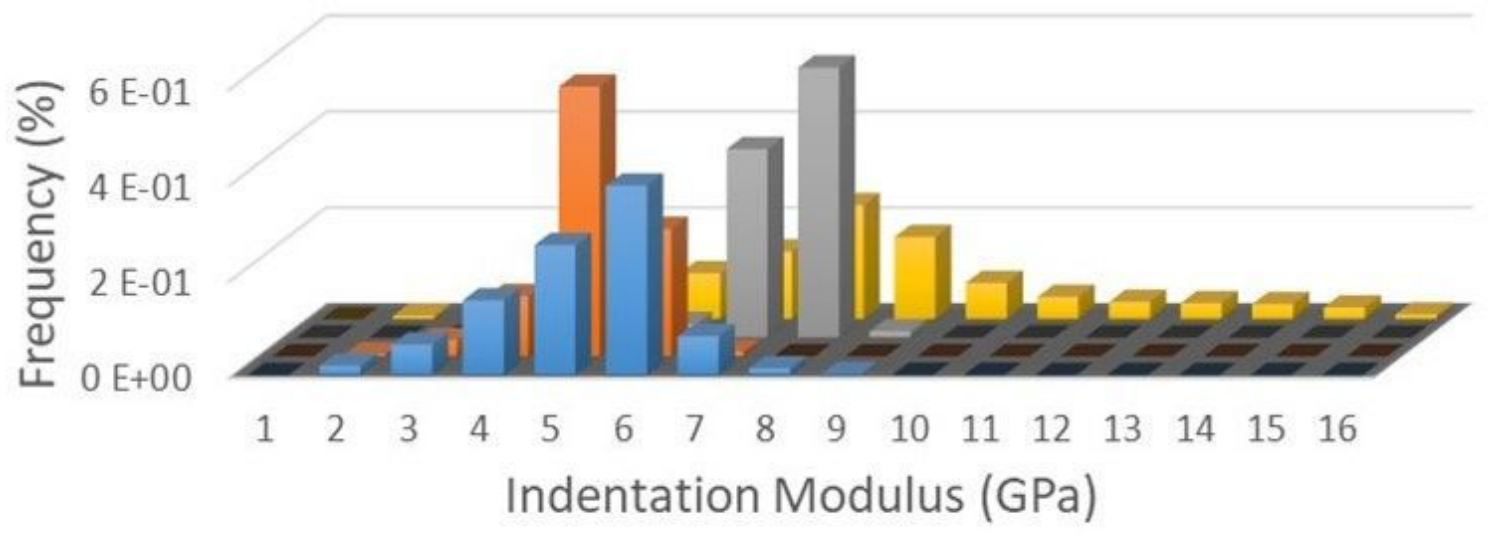

- $\mathrm{PHBHH}(6 \%) \approx \mathrm{PHBHH}(11 \%) \quad \mathrm{PLA}=\mathrm{PHBHV}$

\section{Figure 5}

Figure 5 represents the distribution in the indentation modulus for the different beads as measured by PFQNM. Results obtained are consistent with the moduli obtained by nanoindentation. 


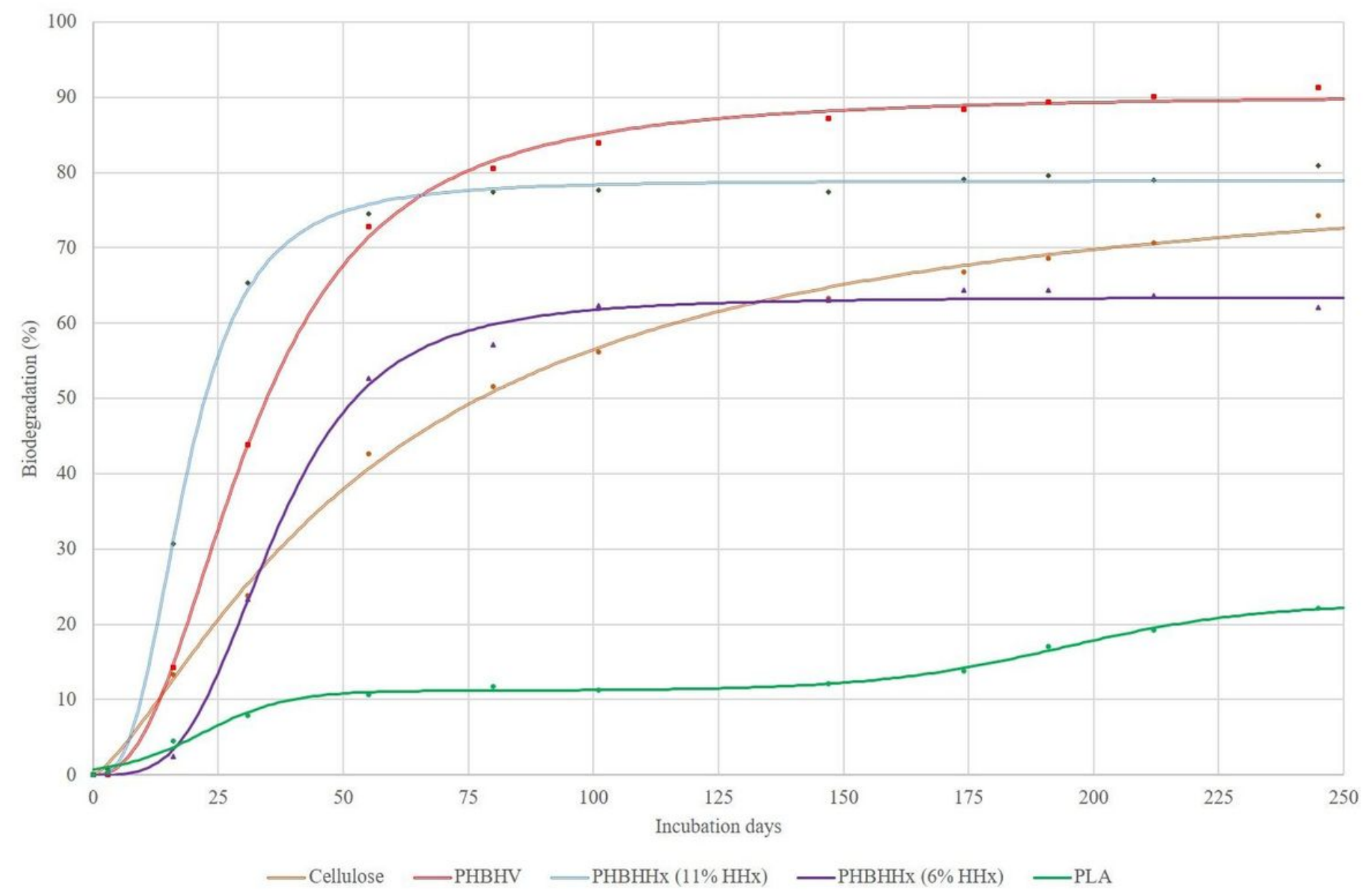

Figure 6

The Figure 6 shows the biodegradability of the different microbeads in seawater. The biodegradation has been performed on marine environment (seawater + sediments) at $25^{\circ} \mathrm{C}$, according to the NF EN ISO 19679 standard. 